\title{
Hydromorphone Hydrochloride Use During Various Interventional Radiology Procedures-Pain Control and Adverse Events: A Case Series Audit Analysis
}

\author{
Thea Moran · Amit Prabhakar · James H. Diaz $\cdot$ Alan David Kaye
}

Received: August 10, 2017 / Published online: October 27, 2017

(C) The Author(s) 2017. This article is an open access publication

\section{ABSTRACT}

Introduction: This project studied pain control and the development of adverse events before, during, and after the administration of hydromorphone hydrochloride for various interventional radiology (IR) procedures.

Methods: We performed a retrospective analysis of 100 patients $($ men $=58$; women $=42$ ) sedated with peri-procedural intravenous (IV) hydromorphone in association with various IR procedures. We stratified the procedures as follows: abscess drainages $(\mathrm{M}=8 ; \mathrm{F}=8)$,

Enhanced content To view enhanced content for this article go to http://www.medengine.com/Redeem/ 73CCF060116FCBD0.

Electronic supplementary material The online version of this article (doi:10.1007/s40122-017-0083-4) contains supplementary material, which is available to authorized users.

T. Moran $(\bowtie) \cdot J$. H. Diaz · A. D. Kaye

Department of Anesthesiology, Louisiana State

University Health Sciences Center, New Orleans, LA, USA

e-mail: theam_90250@yahoo.com

A. Prabhakar

Department of Anesthesiology, Emory School of Medicine, Atlanta, GA, USA

\section{J. H. Diaz}

School of Public Health, School of Medicine, Louisiana State University Health Sciences Center, New Orleans, LA, USA arteriograms $(\mathrm{M}=1 ; \mathrm{F}=0)$, biliary interventions $(\mathrm{M}=3 ; \mathrm{F}=2)$, bone biopsies $(\mathrm{M}=2$; $\mathrm{F}=2)$, non-bone biopsies $(\mathrm{M}=26 ; \mathrm{F}=19)$, non-tunneled venous catheters $(\mathrm{M}=1 ; \mathrm{F}=1)$, tunneled venous catheters $(\mathrm{M}=7 ; \mathrm{F}=5)$, embolization $(\mathrm{M}=4 ; \mathrm{F}=0)$, IVC filter placement $(\mathrm{M}=1 ; \mathrm{F}=1)$, nephrostomy tube placement $(\mathrm{M}=1 ; \mathrm{F}=4), \quad$ and percutaneous nephrolithotomy tube placements $(\mathrm{M}=4$; $\mathrm{F}=0$ ). We recorded the pre-, intra-, and post-procedure pain scores [numeric rating scale (NRS) with $0=$ no pain to $10=$ most pain] for each of the stratifications. We also recorded the total dose of hydromorphone and midazolam hydrochloride received by each gender, as well as whether any men or women received either naloxone hydrochloride or any antiemetic. Lastly, the investigators recorded the development of hypotension following hydromorphone administration and/or hypoxia as well as the need for opioid-induced intensive care unit (ICU) admission. The investigators used unpaired, two-tailed $t$ tests, and either Yates-corrected Chi-squares or two-tailed Fisher's exact tests for continuous and categorical variables, respectively. The difference was statistically significant if $p<0.05$.

Results: There was no significant difference between men and women for either mean age $(\mathrm{M}=50$ years; $\mathrm{F}=53.4$ years) or mean pre-procedural pain scores $(\mathrm{M}=1.31 ; \mathrm{F}=0.55)$. There was no statistically significant difference in numbers of men or women for each procedure 
stratification. The highest mean pre-procedure pain score was in men undergoing percutaneous nephrostomy tube placement (mean 5, SD 0). The highest mean intra-procedure pain score was in men undergoing abscess drainages (mean 2, SD 2.3). The highest mean post-procedure pain score was in men undergoing abscess drainages (mean 1.5, SD 3.5). The only mean scores that were significantly different between men and women were in pre- $(\mathrm{M}=2.5$; $\mathrm{F}=0.6 ; p=0.006)$ and intra-procedural $(\mathrm{M}=2$; $\mathrm{F}=0.5 ; p=0.0001)$ pain scores for abscess drainages. There was no statistically significant difference in the dose of either hydromorphone $(\mathrm{M}=1.3 ; \mathrm{F}=1.3) \quad$ or midazolam $\quad(\mathrm{M}=1.3$; $\mathrm{F}=1.3$ ) administered. There was no statistically significant difference in opioid-induced nausea $(\mathrm{M}=1 ; \quad \mathrm{F}=3)$. One female experienced hypotension and one male experienced hypoxia within $6 \mathrm{~h}$ of hydromorphone administration. There were neither opioid-related ICU admissions nor naloxone administrations.

Conclusions: This preliminary study indicates that IV hydromorphone \pm midazolam may be a safe and effective analgesic and sedative combination for adult patients undergoing IR procedures.

Keywords: Efficacy; Hydromorphone; Interventional radiology; Midazolam; Morphine; Pain; Side effects

\section{INTRODUCTION}

Advancements in technique have permitted the performance of surgical and other invasive procedures traditionally limited to the operating room to be expanded to non-operating room locations. Pain control is mandatory for the effective performance of surgical procedures. As the performance of surgical, or invasive, procedures have expanded outside of the operating room, so has the need for personnel who can perform effective, safe periprocedural pain control. Moderate, or conscious, sedation is widely used to alleviate procedure-associated discomfort outside of the operating room because it is easily learned and avoids the risks associated with deep sedation. Conscious sedation is defined by the American Society of Anesthesiologists as a drug-induced depression of consciousness in which patients respond purposefully to verbal commands, are able to maintain spontaneous ventilation and cardiovascular function, and do not require adjuncts to maintain a patent airway [1]. Typical pharmacologic regimens for conscious sedation include a mild amnestic or anxiolytic and opioids for pain control.

Fentanyl is a commonly used opioid for conscious sedation with primarily analgesic and mild sedative effects. Compared with morphine, fentanyl has 100 times the analgesic potency with less reported nausea. Fentanyl's onset of action is almost immediate via interaction of mu-opioid receptors and has a usual duration of action of 30-60 min when given intravenously (IV). However, when given in large doses, fentanyl alters respiratory rate, alveolar ventilation, and $\mathrm{CO}_{2}$ sensitivity, which can lead to apnea and hypoxia. The respiratory depressant effects are potentiated when given in combination with other commonly administered medications in the IR suite, such as the benzodiazepine midazolam. Fentanyl is also associated with the rare, but significant, stiff chest syndrome where the thoracoabdominal muscles contract after the administration of fentanyl. There is documentation of stiff chest syndrome occurring after the administration of analgesic as well as anesthetic doses [2-5]. Stiff chest syndrome needs to be immediately recognized and treated. The FDA has approved fentanyl for use in the perioperative period in association with general and regional anesthesia [6].

Hydromorphone is another opioid that is used primarily for analgesia. It has 4-8 times the analgesic potency of morphine [7]. Analgesia usually occurs within 15 min of IV injection. Recommended parenteral dosing is every $2-6 \mathrm{~h}$ [7-9]. Similar to other opioids, hydromorphone reduces the responsiveness of the brainstem respiratory centers to increases in carbon dioxide tension, which results in respiratory depression. The respiratory-depressant effect is potentiated by sedative hypnotics. Nausea is one of the most frequent adverse events associated with hydromorphone [8]. Hydromorphone does not have 
any known drug-specific reactions. Hydromorphone is indicated for the management of moderate to severe pain [8].

While fentanyl is an effective and efficient drug, it does present hazards that non-anesthesia personnel may be unaware of and unprepared to handle. We report our experiences at our institution using hydromorphone, with or without a sedative-hypnotic, as a parenteral analgesic during IR procedures. To the best of our knowledge, this is the first report on the uses and outcomes of intravenous hydromorphone as a sedative analgesic during IR procedures.

\section{METHODS}

We selected 100 patients who had received intravenous (IV) hydromorphone in the course of an IR procedure performed at Louisiana State University Interim Hospital in New Orleans, Louisiana. The researchers selected the patients retrospectively and consecutively starting with procedures performed July 31, 2013. The investigators reviewed the medical records via EPIC (Epic Systems Corporation, Verona, WI, USA). We only included patients who had received sedoanalgesia exclusively from the IR nursing staff. All patients received subcutaneous lidocaine, $1 \%$, locally at the site of skin entrance during the procedures. We used the following exclusion criteria: $<18$ years, prisoners, mental incapacitation, admitted to the hospital > 30 days. The investigators recorded the following for each patient: age and sex; procedure(s) performed; comorbidities; hydromorphone dose; midazolam dose; pre-, intra-, and postprocedure pain scores; opioid-associated nausea (emesis, antiemetic adminstration); naloxone hydrochloride dose; hypotension $(\mathrm{SBP}<100 \mathrm{mmHg}) ; \quad$ hypoxia $\left(\mathrm{O}_{2}\right.$ saturation $<93 \%$ ); PACU admission. If $>1$ procedure occurred while in IR, the investigators only used data pertinent to the most painful procedure. Nurses assigning the pain scores used either a numeric score given by the patient or gave a numeric score that correlated with a Wong Facial pain score [10]. We used the pain score at transfer to IR as the preprocedure pain score and we used the pain score closest to the time at transfer from the IR suite as the postprocedure pain score; the mean of the pain scores between timeout and procedure completion were the intraprocedure pain scores. The investigators considered a complication was likely related to the hydromorphone if it occurred $<6 \mathrm{~h}$ from administration based on the recommended dosing of IV hydromorphone every $2-6 \mathrm{~h}$ as necessary for pain control [7-9]. This article does not contain any new studies with human or animal subjects performed by any of the authors. This study and its protocol (including the omission of patient consent in this study involving $100 \%$ retrospective medical record review) was reviewed and approved by the Institutional Review Board (IRB) of the Louisiana State University Interim Hospital (IRB number: 8389). Continuous variables were compared for statistically significant differences by unpaired, two-tailed $t$ tests. Categorical variables were compared for statistically significant differences by either Yates-corrected Chi-squares for larger samples or by Fisher's exact tests when outcomes were five observations or less per cell. Following standard statistical protocol, the surrogate (or "dummy") variable 1 was substituted for any Fisher's exact $2 \times 2$ cell with 0 observations. Differences were statistically significant if $p<0.05$.

\section{RESULTS}

The study population consisted of 58 men and 42 women; the mean age difference between genders was not statistically significant (50 vs. 53.5 years, $p=0.168$ ). There was no statistically significant difference in pre-procedure pain scores between all men and all women (1.31 vs. $0.55, p=0.128)$. Each of the 11 IR procedures studied had numbers that were well matched between men and women (Table 1).

The pre-, intra-, and post-procedure pain scores were well matched between genders except in the case of abscess drainages which were significantly different both pre-procedurally (men $=2.5$, women $=0.6, p=0.006)$ and intra-procedurally $($ men $=2.0$, women $=0.5$, $p=0.0001)$. The highest mean pain score was 
Table 1 Baseline characteristics of gender-stratified populations

\begin{tabular}{|c|c|c|c|c|c|}
\hline Baseline characteristics & $\begin{array}{l}\text { Males } \\
(n=58)\end{array}$ & $\begin{array}{l}\text { Females } \\
(n=42)\end{array}$ & Chi-square values & $\begin{array}{l}t \text { test } \\
\text { values }\end{array}$ & $p$ values \\
\hline Age $($ mean $\pm S D)$ & $50 \pm 12.4$ & $53.5 \pm 12.5$ & $\begin{array}{l}\text { Not applicable } \\
\text { (NA) }\end{array}$ & 1.388 & 0.168 \\
\hline $\begin{array}{l}\text { Pre-procedure pain score } \\
\qquad(\text { mean } \pm S D)\end{array}$ & $1.31 \pm 2.85$ & $0.55 \pm 1.73$ & NA & 1.534 & 0.128 \\
\hline \multicolumn{6}{|c|}{ Types of interventional radiology (IR) procedures } \\
\hline Abscess drainage tube & 8 & 8 & 0.186 & NA & 0.666 \\
\hline Arteriogram & 1 & 0 & $\begin{array}{l}\text { Fisher's exact } \\
p \text { value }\end{array}$ & NA & 1.000 \\
\hline Biliary intervention & 3 & 2 & $\begin{array}{l}\text { Fisher's exact } \\
p \text { value }\end{array}$ & NA & 1.000 \\
\hline Bone biopsy & 2 & 2 & $\begin{array}{l}\text { Fisher's exact } \\
p \text { value }\end{array}$ & NA & 1.000 \\
\hline Non-bone biopsy & 26 & 19 & 0.027 & NA & 0.871 \\
\hline Non-tunneled venous catheter & 1 & 1 & $\begin{array}{l}\text { Fisher's exact } \\
p \text { value }\end{array}$ & NA & 1.000 \\
\hline Tunneled venous catheter & 7 & 5 & $\begin{array}{l}\text { Fisher's exact } \\
p \text { value }\end{array}$ & NA & 1.000 \\
\hline Embolization & 4 & 0 & $\begin{array}{l}\text { Fisher's exact } \\
p \text { value }\end{array}$ & NA & 0.395 \\
\hline Inferior vena cava (IVC) filter & 1 & 1 & $\begin{array}{l}\text { Fisher's exact } \\
p \text { value }\end{array}$ & NA & 1.000 \\
\hline Nephrostomy tube & 1 & 4 & $\begin{array}{l}\text { Fisher's exact } \\
p \text { value }\end{array}$ & NA & 0.158 \\
\hline Percutaneous nephrolithotomy tube & 4 & 0 & $\begin{array}{l}\text { Fisher's exact } \\
p \text { value }\end{array}$ & NA & 0.395 \\
\hline
\end{tabular}

pre-procedural in men scheduled for nephrostomy tube placement (mean 5). The highest intra-procedural pain score was in men during abscess drainages (mean 2.0). The highest post-procedure pain score was in women after receiving a nephrostomy tube (mean 3.5). There was no significant difference between men and women in total doses of either periprocedural hydromorphone or midazolam. Three men received only hydromorphone without midazolam for periprocedural pain control (Table 2).
There were very few adverse events. The events that did occur were well matched in number between the genders (Table 3). One man and three women required an antiemetic within $6 \mathrm{~h}$ of receiving the periprocedural hydromorphone; these calculations excluded patients who had received the antiemetic either as part of an operative protocol (three men, 0 women) or because the patient had medical conditions that predisposed them to nausea (two men, two women). One woman experienced hypotension within $6 \mathrm{~h}$ of receiving the 
Table 2 Pain scores in gender-stratified populations for different IR procedures

\begin{tabular}{|c|c|c|c|c|}
\hline Interventional radiology (IR) procedures & Males $(n=58)$ & Females $(n=42)$ & $t$ values & $p$ values \\
\hline \multicolumn{5}{|l|}{ IR abscess drainage } \\
\hline Pre-pain score & $2.5 \pm 4.1$ & $0.6 \pm 1.8$ & 2.811 & $0.006^{*}$ \\
\hline Intra-pain & $2.0 \pm 2.3$ & $0.5 \pm 0.9$ & 4.006 & $0.0001^{*}$ \\
\hline Post-pain & $1.5 \pm 3.5$ & 0 & NA & \\
\hline \multicolumn{5}{|l|}{ IR arteriogram } \\
\hline Pre-pain score & 2 & 0 & NA & \\
\hline Intra-pain & 0.2 & 0 & NA & \\
\hline Post-pain & 0 & 0 & NA & \\
\hline \multicolumn{5}{|l|}{ IR biliary intervention } \\
\hline Pre-pain score & 0 & 0 & NA & \\
\hline Intra-pain & 0 & $0.7 \pm 0.9$ & NA & \\
\hline Post-pain & 0 & 0 & NA & \\
\hline \multicolumn{5}{|l|}{ IR bone biopsy } \\
\hline Pre-pain score & 0 & 0 & NA & \\
\hline Intra-pain & 0 & 0 & NA & \\
\hline Post-pain & 0 & 0 & NA & \\
\hline \multicolumn{5}{|l|}{ IR non-bone biopsy } \\
\hline Pre-pain score & $1.0 \pm 2.5$ & $0.3 \pm 1.1$ & 1.698 & 0.093 \\
\hline Intra-pain & $0.31 \pm 0.67$ & $0.08 \pm 0.34$ & 2.041 & 0.044 \\
\hline Post-pain & 0 & $0.11 \pm 0.46$ & NA & \\
\hline \multicolumn{5}{|l|}{ IR non-tunneled venous catheter } \\
\hline Pre-pain score & 0 & 0 & NA & \\
\hline Intra-pain & 0 & 0.8 & NA & \\
\hline Post-pain & 0 & 0 & NA & \\
\hline \multicolumn{5}{|l|}{ IR tunneled venous catheter } \\
\hline Pre-pain score & $2.3 \pm 3.9$ & 0 & NA & \\
\hline Intra-pain & $0.91 \pm 1.7$ & 0 & NA & \\
\hline Post-pain & 0 & 0 & NA & \\
\hline \multicolumn{5}{|l|}{ Embolizations } \\
\hline Pre-pain score & 0 & 0 & NA & \\
\hline Intra-pain & $0.13 \pm 0.25$ & 0 & NA & \\
\hline Post-pain & 0 & 0 & NA & \\
\hline
\end{tabular}


Table 2 continued

\begin{tabular}{|c|c|c|c|c|}
\hline Interventional radiology (IR) procedures & Males $(n=58)$ & Females $(n=42)$ & $t$ values & $p$ values \\
\hline \multicolumn{5}{|l|}{ IVC filters } \\
\hline Pre-pain score & 0 & 0 & NA & \\
\hline Intra-pain & 0 & 0 & NA & \\
\hline Post-pain & 0 & 0 & NA & \\
\hline \multicolumn{5}{|l|}{ Nephrostomy tubes } \\
\hline Pre-pain score & 5.0 & $3.3 \pm 3.8$ & NA & \\
\hline Intra-pain & 0.3 & $2.2 \pm 2.0$ & NA & \\
\hline Post-pain & 0 & $3.5 \pm 4.1$ & NA & \\
\hline \multicolumn{5}{|l|}{ Percutaneous nephrolithotomy tubes } \\
\hline Pre-pain score & $1.8 \pm 3.5$ & 0 & NA & \\
\hline Intra-pain & 0 & 0 & NA & \\
\hline Post-pain & 0 & 0 & NA & \\
\hline
\end{tabular}

hydromorphone. After receiving a tunneled dialysis catheter, she was taken directly to dialysis where she experienced the hypotensive episode; the lowest recorded systolic blood pressure was $63 \mathrm{mmHg}$, which was $2 \mathrm{~h}$ after receiving the hydromorphone. One man experienced hypoxia after nephrostomy placement; his transcutaneous $\mathrm{O}_{2}$ saturation was $94-100 \%$ on 2L nasal cannula (NC) immediately post nephrostomy tube placement and dropped to $89-91 \% 1 \mathrm{~h}$ post-procedure. He was drowsy but arousable and in no acute distress. He was placed on $100 \%$ non-rebreathing facemask, which promptly brought the $\mathrm{O}_{2}$ saturation $>93 \%$. There were no opioid-related PACU admissions. There were no naloxone administrations.

\section{DISCUSSION}

Hydromorphone controlled the pain experienced by patients undergoing the IR procedures. The highest mean intraprocedural pain score was 2.0 (mild pain) and the highest mean postprocedural pain score was 3.5 (more moderate than mild pain). The pain was safely controlled; $4 \%$ of patients either vomited or received antiemetics and $1 \%$ experienced hypoxia following hydromorphone administration probably due to removal of the procedural stimulus. It is uncertain whether the patient would have experienced the hypotension on dialysis regardless of the hydromorphone administration but the hydromorphone may have contributed to its severity. All adverse effects were able to be managed conservatively without ICU admission. Naloxone administration was not necessary for any of the patients.

After a thorough review of the literature, we could find no articles related to periprocedural hydromorphone use. Uses for hydromorphone in IR have been limited to patient-controlled analgesia and post-discharge pain control. Hydromorphone has historically been used for chronic management of moderate to severe pain. We may be seeing an increase in hydromorphone use in an acute setting in the future. Emergency departments have been seeing an increase in hydromorphone use after institution of JCAHO's "safe use of opioids in hospitals" program, which emphasized the adverse effects of prescribing morphine in renal failure patients; fentanyl has not shown a similar increase in use mostly because of its difference in metabolism $[11,12]$. 
Table 3 Medication dosages and adverse outcomes in gender-stratified populations receiving IV hydromorphone for perioperative pain control

\begin{tabular}{rllll}
\hline Males $(n=58)$ & Females $(n=42)$ & Chi-square values & $t$ test values & $p$ values (by either) \\
\hline 1. Total hydromorphone doses in $\mathrm{mg} \mathrm{IV}$
\end{tabular}

1. Total hydromorphone doses in $\mathrm{mg}$ IV
Total dose
$1.30 \pm 0.48$
$1.30 \pm 0.51$
NA
0.000
1.000

2. Total midazolam doses in $\mathrm{mg}$ IV
Total dose
$1.30 \pm 0.69$
$1.30 \pm 0.53$
NA
0.000
1.000

3. Patients requiring an antiemetic within $6 \mathrm{~h}$ of receiving hydrochloride
\#
6
5
Fisher's exact
NA
1.000

3a. Patients who received an antiemetic as part of a general anesthetic protocol within $6 \mathrm{~h}$ of receiving hydrochloride
\#
3
0
Fisher's exact
NA
0.637

3b. Patients who received an antiemetic within $6 \mathrm{~h}$ of receiving the hydrochloride but also had condition/symptomatology predisposing to $\mathrm{N} / \mathrm{V}$

$\begin{array}{llllll}\# & 2 & 2 & \text { Fisher's exact } & \text { NA } & 1.000\end{array}$

3c. Patients with opioid-induced N/V
\#
1
3
Fisher's exact
NA
0.307

4. Patients who received hydromorphone and were admitted to the PACU/ICU postoperatively
\#
30
18
0.453
NA
0.501

4a. Patients admitted to the PACU postoperatively for opioid-induced complication

\# $\quad 0 \quad 0 \quad$ NA

5. Patients experiencing opioid-induced hypotension $(\mathrm{SBP}<100 \mathrm{mmHg})$

$\begin{array}{llllll}\# & 0 & 1 & \text { Fisher's exact } & \text { NA } & 1.000\end{array}$

6. Patients experiencing opioid-induced hypoxia $\left(\mathrm{O}_{2} \mathrm{sat}<93 \%\right)$

$\begin{array}{llllll}\# & 1 & 0 & \text { Fisher's exact } & \text { NA } & 1.000\end{array}$

7. Patients needing opioid-reversal with naloxone (for over-sedation

$\begin{array}{llll}\text { \# } & 0 & 0 & \text { NA }\end{array}$

The most obvious limitation of the study is its small sample size and the even smaller sizes of the subgroups after stratification. Nine out of $22(41 \%)$ of the cells in Table 1 had either 1 or 0 patients that had endured a particular procedure. Only eight men and eight women had abscess drainage performed, which limits the utility of an outcomes analysis. Only 22 of the 100 patients in this study underwent procedures considered to be relatively more painful (biliary interventions, bone biopsies, embolizations, percutaneous nephrostomies, percutaneous nephrolithotomy access placement). On a similar note, only four of our cases were embolization procedures, whereupon our literature search showed most of the literature regarding pain control and interventional radiology procedures were for uterine artery embolization and chemoembolization [13-19]. A larger cohort of patients undergoing more painful procedures would give a better estimate of hydromorphone's true analgesic ability in procedural IR settings. Hydromorphone's effectiveness directly compared to fentanyl also 
limits the study's conclusions; case-matched controls would have given more substance to the study's conclusions. Lastly, the study design's retrospective nature is a limiting factor. Prospective studies directly comparing the efficacy, safety, and cost-effectiveness of fentanyl and hydromorphone would be helpful in answering many of the aforementioned questions.

\section{CONCLUSIONS}

Preliminary evidence shows that IV hydromorphone can be a safe and effective analgesic for use during IR procedures. Further studies with larger sample sizes and prospective design are warranted to explore hydromorphone's potential clinical efficacy and cost-effectiveness.

\section{ACKNOWLEDGEMENTS}

No funding or sponsorship was received for this study or publication of this article. The article processing charges were funded by the authors (LSU Dept of Anesthesiology). All named authors meet the International Committee of Medical Journal Editors (ICMJE) criteria for authorship for this manuscript, take responsibility for the integrity of the work as a whole, and have given final approval for the version to be published.

Disclosures. Dr. Thea Moran, Dr. Amit Prabhakar, Dr. James Diaz, and Dr. Alan Kaye have nothing to disclose.

Compliance with Ethics Guidelines. This article does not contain any new studies with human or animal subjects performed by any of the authors. This study and its protocol (including the omission of patient consent in this study involving $100 \%$ retrospective medical record review) was reviewed and approved by the Institutional Review Board (IRB) of the Louisiana State University Interim Hospital (IRB number: 8389).
Data Availability. Datasets obtained during the study are included in this published article/ as supplementary information files

Open Access. This article is distributed under the terms of the Creative Commons Attribution-NonCommercial 4.0 International License (http://creativecommons.org/licenses/ by-nc/4.0/), which permits any noncommercial use, distribution, and reproduction in any medium, provided you give appropriate credit to the original author(s) and the source, provide a link to the Creative Commons license, and indicate if changes were made.

\section{REFERENCES}

1. American Society of Anesthesiologists Task Force on Sedation, and Analgesia by Non-Anesthesiologists. Practice guidelines for sedation and analgesia by non-anesthesiologists. Anesthesiology. 2002;96(4):1004-17.

2. Çoruh B, Tonelli MR, Park DR. Fentanyl-induced chest wall rigidity. Chest. 2013;143(4):1145-6.

3. Phua CK, Wee A, Lim A, Abisheganaden J, Verma A. Fentanyl-induced chest wall rigidity syndrome in a routine bronchoscopy. Respir Med Case Rep. 2017;20:205-7.

4. Vaughn RL, Bennett CR. Fentanyl chest wall rigidity syndrome-a case report. Anesth Prog. 1981;28(2):50-1.

5. Gaffney RR, Schreibman IR. Serotonin syndrome in a patient on trazodone and duloxetine who received fentanyl following a percutaneous liver biopsy. Case Rep Gastroenterol. 2015;9(2):132-6.

6. US Food and Drug Administration. Fentanyl citrate injection, USP. https://www.accessdata.fda.gov/ drugsatfda_docs/label/2013/016619s034lbl.pdf. Accessed 29 Mar 2017.

7. Moran T, Kaye AD, Mai A, Bok LR. Sedation, analgesia, and local anesthesia: a review for general and interventional radiologists. RadioGraphics. 2013;33:E47-60.

8. Dilaudid Injection and HP Injection (hydromorphone hydrochloride). PDR.net. http://www.pdr. net/drug-information/dilaudid-injection-and-hpinjection?druglabelid=490. Accessed 11 Sept 2017. 
9. US Food and Drug Administration. Dilaudid and Dilaudid-HP injection: $1 \mathrm{mg} / \mathrm{mL}, 2 \mathrm{mg} / \mathrm{mL}, 4 \mathrm{mg} /$ $\mathrm{mL}$, and $10 \mathrm{mg} / \mathrm{mL}$ (hydromorphone hydrochloride) C-II. https://www.accessdata.fda.gov/drugsa tfda_docs/label/2009/019034s018lbl.pdf. Accessed 11 Sept 2017.

10. Wong Baker Faces Foundation. Faces of Pain Care. http://www.wongbakerfaces.org. Accessed 11 Sept 2017.

11. Sutter ME, Wintemute GJ, Clarke SO, Roche BM, Chenoweth JA, Gutierrez R, et al. The changing use of intravenous opioids in an emergency department. West J Emerg Med. 2015;16(7):1079-83.

12. Tawfic QA, Geoff Bellingham G. Postoperative pain management in patients with chronic kidney disease. J Anaesthesiol Clin Pharmacol. 2015;31(1):6-13.

13. Kim SY, Koo BN, Shin CS, Ban M, Han K, Kim MD. The effects of single-dose dexamethasone on inflammatory response and pain after uterine artery embolisation for symptomatic fibroids or adenomyosis: a randomised controlled study. BJOG. 2016;4:580-7.

14. Noel-Lamy M, Tan KT, Simons ME, Sniderman KW, Mironov O, Rajan DK. Intraarterial lidocaine for pain control in uterine artery embolization: a prospective, randomized study. J Vasc Interv Radiol. 2017;28(1):16-22.
15. Zhao JB, Luo ZL, Feng C, Zeng QL, He XF, Li YH, et al. Effects of the intermittent injection with super-low pressure on the postoperative pain control during the uterine artery embolization for uterine myoma. Int $\mathrm{J}$ Clin Exp Med. 2015;8(8):14303-7.

16. Bilhim T, Pisco JM. The role of nonsteroidal anti-inflammatory drugs (NSAIDS) in the management of the post-embolization symptoms after uterine artery embolization. Pharmaceuticals. 2010;3:1729-38.

17. Hartnell GG, Gates J, Stuart K, Underhill J, Brophy DP. Hepatic chemoembolization: effect of intraarterial lidocaine on pain and postprocedure recovery. Cardiovasc Intervent Radiol. 1999;22:293-7.

18. Lv N, Kong Y, Mu L, Pan T, Xie Q, Zhao M. Effect of perioperative parecoxib sodium on postoperative pain control for transcatheter arterial chemoembolization for inoperable hepatocellular carcinoma: a prospective randomized trial. Eur Radiol. 2016;26(10):3492-9.

19. Kogut MJ, Chewning RH, Harris WP, Hippe DS, Padia SA. Postembolization syndrome after hepatic transarterial chemoembolization: effect of prophylactic steroids on postprocedure medication requirements. $\mathrm{J}$ Vasc Interv Radiol. 2013;24(3):326-31. 